\title{
Digital accounting platform
}

\author{
Galina Krokhicheva ${ }^{1}$, Iulia Mezentseva ${ }^{1,}$, Eduard Arkhipov ${ }^{1}$, and Elena Evstafieva ${ }^{2}$ \\ ${ }^{1}$ Don State Technical University, 1, Gagarin sq., 344010, Rostov-on-Don, Russia \\ ${ }^{2}$ Rostov State University of Economics (RINH), 105/42, B. Sadovaya str., 344002, Rostov-on-Don, \\ Russia
}

\begin{abstract}
The article is devoted to the accounting processes organization study in digital economy. The multifunctional qualimetry use in digital economy will lead to a fundamental change in the management and decisionmaking organization in all major areas. The authors described digital regulation and decision making in conditions of risk and uncertainty in a multi-level aspect. A complex of digital mechanisms and platform solutions is proposed. It allows organizing the digital accounting systems based on the platform solutions. The "Digital Information Accounting Platform" pattern, based on an engineering chart of accounts, has been developed.
\end{abstract}

\section{Introduction}

Accounting and management in their development have gone through several major stages:

Stage 1 . The recording of economic activity facts on the basis of a one-time recording (from the moment of writing until the double-recording invention by Luca Pacioli), the creation of an economic and legal base in the field of property management relations. This stage had lasted for more than 3000 years (Egypt, Assyria, China) up to the 15th century.

Stage 2. It took 200 years (XV - XVI centuries): it is characterized by the creation of a financial accounting and management system based on the widespread introduction of mathematical methods: balance sheets, turnover sheets, linking indicators, reconciling calculations.

Stage 3. The period XVII - XVIII centuries is characterized by a symbiosis of mathematics and law: determining the organization value, managing financial results, creating an audit system, reporting. As a result, property management arose at this stage.

Stage 4. The period XIX - XX centuries passed under the formation flag of the accounting and control systems in management direction at both micro and macro levels.

In the last 50 years of the 20th century, accounting started being formed as the most important area of its 10 main types management, including strategy, tactics, systems management, personnel management, etc. At the same time, accounting and finance are positioned the first among all management types [1].

Internet technologies have made revolutionary changes in the economy structure; therefore, over the past 20 years we have been talking about the upcoming era of the digital economy [2,3]. These processes led to the fact that the world has come to the third paradigm of accounting and management development, called engineering, digital, triple, digital, API,

* Corresponding author: mezentseva.y.r@mail.ru 
etc., which entails the digital systems' creation in accounting, analysis, control and management based on the use of digital technologies and platform solutions, such as megabookkeeping, triple bookkeeping, an engineering chart of accounts as an information platform for accounting, control, analysis and management, aggregated accounting and control postings, distributed ledger, permanent recording, hundreds of computer programs providing management in the mode online innovation processes [4].

To be included in global trends, Russia should not only be engaged in the individual niche solutions' development, but also effectively achieve the global goals in digitalizing the accounting system $[5,6]$.

\section{Theoretical and methodological basis of the study}

The trust architecture in the system of digital technologies and platform solutions is based on four positions:

1. Behavioral economics operates on the basis of the "Internet values" use, reflected in monetary terms: human, structural, educational capital, positions of an effective contract, objects and processes for implementing the roadmap. Digital technologies provide accurate copying and transfer to many users at almost no cost, which makes it possible to organize digital management of many behavioral objects at the micro, meso and macro levels [7].

2. Distributed registry technology includes any number of participants equipped with software and cloud (private, public) of information storage. Distributed registry technology ensures data transparency for each participant, control and immutability of Internet things without or with the participation of a third party.

3. The basis of trust architecture is a transaction, that is, a programmed action in the information field of a distributed registry, performed on the basis of a smart contract, that is, a corresponding computer program [8].

A smart contract ensures the functioning of any management objects in the behavioral economy of both individual participants and the team as a whole: the implementation of an effective contract, roadmap, insurance payments, fees, etc.

4. The inclusiveness of digital registries (start and end operators, transaction systems) ensures transparency of information, security, control and data receipt that the traditional economy cannot provide: a financial risk zone, a security margin, predetermining analytical decisions of participants in a behavioral economy.

The first paradigm of accounting and management was built on a one-time record and formed a system of office (estimated) accounting and management.

The second is based on the principle of double entry, which served as the basis for many modern accounting and management systems.

The third one, called digital, engineering, singular, is focused on managing property (intellectual, financial, material, etc.) in an online market assessment, based on the accounting engineering tools, economic aggregates, aggregated transactions and algorithms, matrices, computer programs, engineering charts of accounts, accounting architectonics, etc.

The digital system operates on the 3rd record:

- The 2 nd record in the system of financial and permanent accounting, provides the internal and external control;

- The 2nd entry in the system of managerial, strategic, transactional accounting provides management of more than 200 economic processes;

- The 2nd entry on the financial accounting and distributed register basis provides the management of intellectual, environmental, social and other types of capital in order to manage the brand, roadmap, budget financing, effective contract and other social processes.

Digital accounting in modern conditions is developed in two directions $[9,10]$ :

- the adaptive digital accounting system functioning; 
- creation and testing of an innovative digital accounting system.

Adaptive digital accounting is characterized by the following main positions:

- The basis of accounting and management is an engineering chart of accounts, in which mega-accounts being the aggregated economic aggregates (the main balance sheet formula, sections of the balance sheet, sections of the chart of accounts, etc.) are mounted;

- digital accounting is represented by a system of accounting engineering tools;

- digital work programs include a start and end operator, a system of aggregated and hypothetical accounting entries, designed in the form of algorithms system and registered with the Rospatent of the Russian Federation;

- the final operator is represented by the aggregated (net assets) and disaggregated (net liabilities) indicators of ownership in the market and fair values, respectively (financial, material, intellectual);

- Digital management of economic processes is carried out on the basis of the definition and use of economic risk zones in management (active - excess resources; passive - lack of resources; neutral - balance of resources and needs) and security margins.

Digital accounting is also built on the basis of an engineering accounts chart, financial accounting operates on the basis of aggregated economic aggregates characterizing the financial condition of the institutional unit online (assets, liabilities, capital, income, expenses, financial result) based on the aggregated accounting entries' use. The production, managerial, transactional, strategic types of digital accounting operate on the basis of appropriate computer programs embedded in the engineering chart of accounts based on the corresponding set of mega-accounts:

- digital analytical production accounting;

- digital management accounting;

- digital management financial accounting;

- digital strategic accounting;

- digital transaction accounting.

Adaptive and innovative digital accounting as well as management systems are widely implemented in the practice of leading foreign companies, which meets the requirements of a singular turn in management.

The Key Features of Digital Management Mechanisms ca be described as follows:

- digital programs are built using engineering graphs, matrices, algorithms, Petri nets, Data Envelopment Analysis, etc.;

- Engineering mechanisms, with the help of which the accounting systems are organized in different time horizons (current, perspective and strategic), allow orientation to specific business processes and specified planning horizons. Carrying out the breakdown and gradation of forecast horizons according to a given phases, assuming multivariance of estimates, it becomes possible at any given moment in time to take into account various restrictive factors and calculate their influence online. This is characteristic of a stochastic economy;

- the forecast horizon of digital mechanisms in the form of a mega balance system is oriented to the periods of different durations and is based on the changes indicators in ownership in the form of an aggregated indicator (net assets) and a disaggregated indicator (net liabilities); - digital programs do not require a specific enterprise;

- the initial and final operators are the value aggregates (Nobel Prize laureate formula, balance sections, mega accounts, basic ownership equation: Assets = Capital + Liabilities, etc.);

- computer iterations are integrated and are aimed at increasing or decreasing capital;

- programs give a possibility to determine the security margin and the financial risk area online; 
- the platform is built on the basis of an engineering chart of accounts, a distributed register and a permanent record [11];

- the effectiveness of the functioning of the business system is determined in monetary terms in the form of synergism (+), anergism (-);

- The data orchestrator uses the revolutionary capabilities of IoT and big data analytics to innovate and create value, including geolocation services, remote monitoring, preventative maintenance, contextual marketing offers and video analytics [12];

- the paradigm of digital behavioral economics comes down to the following triad implementation: Optimum + Equilibrium + Synergism based on digital technologies and platform solutions.

\section{Research and discussion results}

Digital mechanisms integrated into financial, managerial and tax accounting are used in all sectors.

Digital systems of accounting, control and management should be built on the following principles focused on digital economy:

- the design of the digital platform and the functioning of digital technologies equipped with a set of digital mechanisms in the form of a mega balance system is shown in Figure 1;

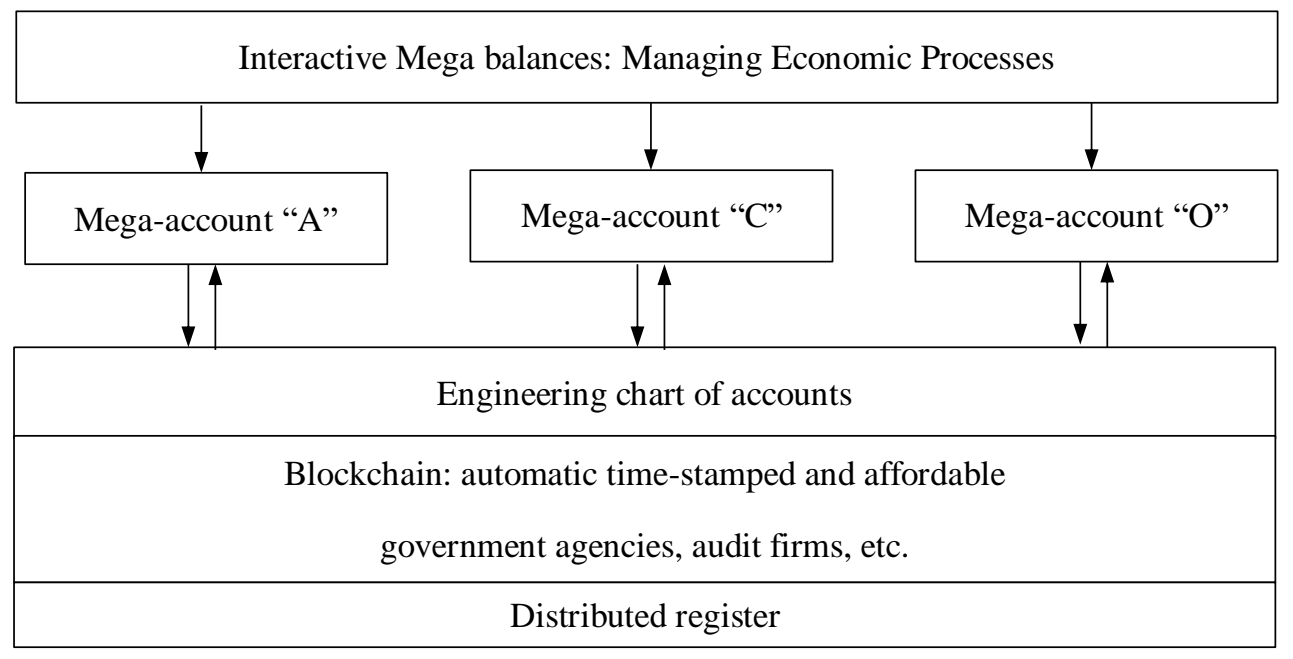

Fig. 1. Digital platform.

- designing the engineering tools providing the financial, intellectual, structural, behavioral, educational and consumer capital management (a mechanism for generating the information field of an engineering chart of accounts is shown in Figure 2);

- management of economic situations and aggregate resource flows;

- formation of an engineering chart of accounts, in which the economic aggregates are megaaccounts, permanent record and distributed register;

- use of aggregated accounting entries focused on the property indicators;

- reserve system management with the definition of security margins and financial risk areas (active, neutral, passive);

- focus on determining the activities' result;

- a general indicator of the organization's activity, the synergy or anergism obtained, focused on the use of financial and intellectual capital and a management road map. 


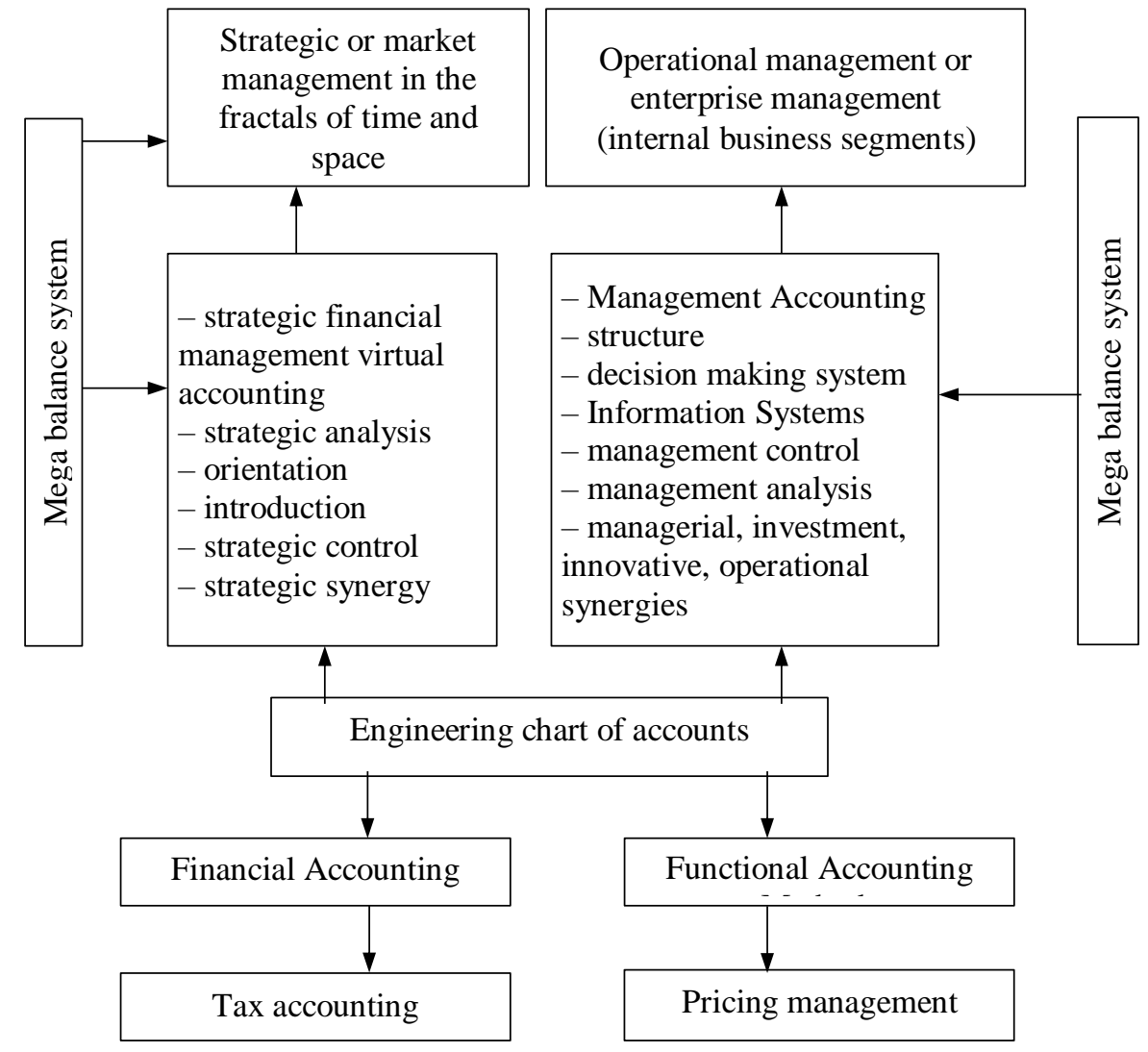

Fig. 2. Information field of an engineering chart of accounts.

A digital platform in the form of an "Engineering chart of accounts" functions to provide all the accounting and reporting sections, and as needed, any of the computer programs based on big data can be used online, for example, to determine the financial risk zone [13].

Based on these positions, the "Digital Information Accounting Platform" pattern developed in Figure 3 has been developed, which is based on an engineering chart of accounts.

The generalized platform mechanism is formed by four main blocks:

I. Mega-account system.

II. Digital multifunctionality.

III. Algorithm system.

IV. Results and mode of operation.

The mega-accounting system provides the relationship between the traditional management system of numerous accounting entries (20-25 thousand units) and the aggregated engineering transactions focused on property management (8-15 units)). 


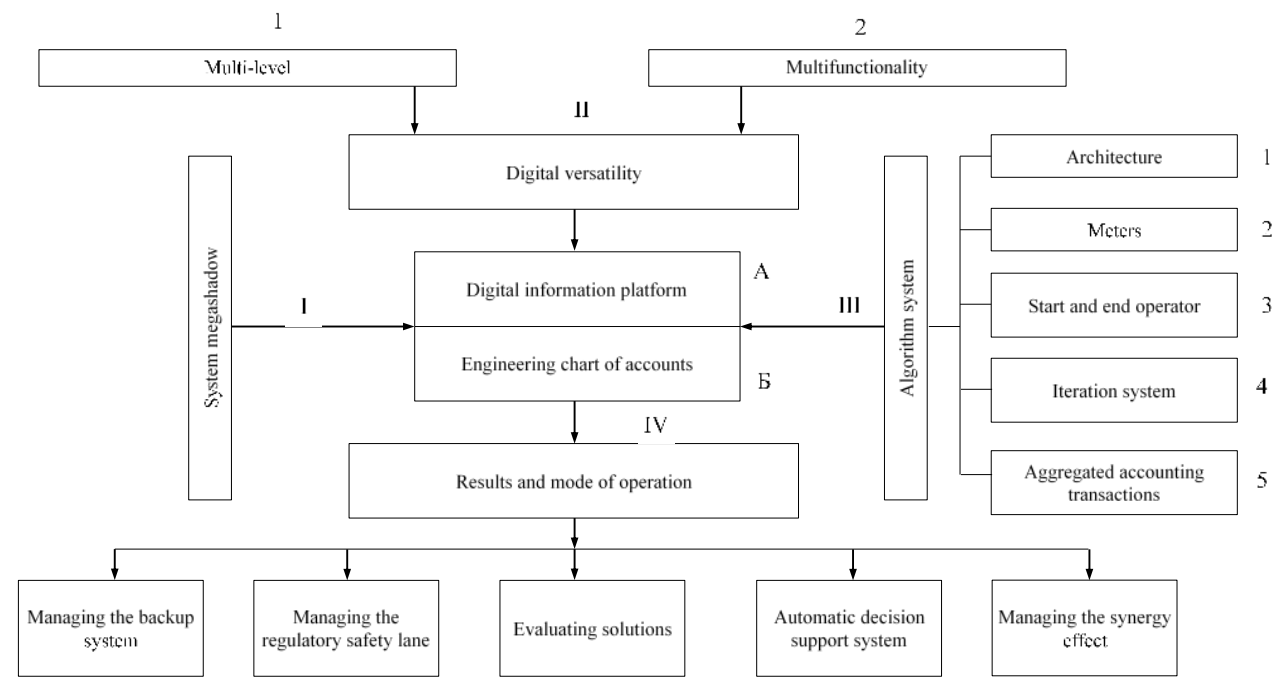

Fig. 3. Pattern "Digital Information Accounting Platform".

Moreover, if the traditional system has already been focused on obtaining the financial results for 3000 years, the digital system allows real-time management of the enterprise's property in market and fair value.

Mega-accounts can be used:

1. $\mathrm{A}=\mathrm{C}+\mathrm{O}$ (3 mega-accounts);

2. $\mathrm{A} 1+\mathrm{A} 2=\mathrm{C}+\mathrm{O} 4+\mathrm{O} 5$ (mega-accounts);

3. A = Co,b (2 mega-accounts),

where the assets: A (total value), A1 (non-current), A2 (current)).

Capital: C (own), Co, b (own and borrowed).

Obligations: O (total value), O4 (long-term), O5 (short-term).

Digital accounting and management provide multifunctional and multi-level management for both the operational activities through the general management organization and the development of the strategic vector.

So, in the field of analysis, this will allow:

- revaluation of input according to the analysis purpose;

- use of aggregated and disaggregated property indicators in the analysis;

- the ability to analyze in network space by the space and time factors;

- the possibility of using such data as financial, managerial, strategic accounting;

- computerization of the analysis process.

The multivariate accounting is formed on the basis of a digital information platform in which a macro-account system is mounted.

The multi-tiered digital platform provides the ability to operate digital systems of managerial, strategic, transactional accounting, control mechanisms and reporting. So, for example, the tiers provide the use of:

- digital mechanisms for managerial, strategic and transactional accounting;

- digital control mechanisms in the form of engineering zero mega balances and specialized control mega balances;

- financial and digital reporting forms.

The use of tiered accounting and management is caused by many factors:

- new types of accounting appeared and improved: managerial, situational-matrix, strategic, transactional, etc.; 
- In turn, the types of accounting were detailed: the management was formed in more than 30 types; strategic includes more than 10 options; situational-matrix - 2-3 options, the resulting transaction is already formed in more than 10 options, etc.;

- accounting objects (value chain, product life cycle, etc.) are constantly being detailed;

- there are more and more features in the accounting methodology, reflected in the form of scopes, i.e. the main directions solved by the financial accounting system: production, financial, social and dozens of specific optics options;

- there are individual characteristics of the accounting organization at enterprises, for example, the information capacity of accounts chart ranges from several thousand to a million accounting and analytical positions;

- the developed management systems are tied to specific features of enterprise accounting (ERP), their implementation requires significant costs. And the program solves, in fact, the typical managerial issues built on a system of indices, coefficients, deviations, etc.

\section{Summary}

According to the experts, in 2040-2050s a fundamentally new turn (jump) in management is expected, called the "singular" one. The use of multifunctional qualimetry in digital economy will lead to a fundamental change in the management and decision-making organization in all major areas.

To do this, it is crucial to distinguish the cause of the problem from its symptom. A common symptom of the problems associated with the fundamental process is the impact of these problems on their associated technologies. In many cases, the problem is not with technology at all. Therefore, it is necessary to distinguish between two options: in which cases the technology really causes the problems, and in which - it is just a symptom of a hidden problem [14].

Overcome the problems of a very cumbersome accounting system that ultimately does not solve many management and control issues, and will allow the creation of digital megaaccounts. Digital accounting multifunctionality is manifested in the fact that it performs functions that are not characteristic of traditional financial, managerial and strategic accounting, but aggregates them.

\section{References}

1. Tkach V I, Shumeyko M V 2012 International Accounting 18 2-9

2. 2019 Digital Economy Report Value Creation and Benefit: Implications for Developing Countries (Geneva: United Nations)

3. Abdrakhmanova G I, Vishnevsky K O, Gokhberg L M 2020 Digital economy: 2020: a $\begin{array}{lll}\text { brief } & \text { statistical } & \text { compilation } \\ \text { https://issek.hse.ru/mirror/pubs/share/323871553 }\end{array}$

(Moscow: HSE)

4. Tkach V I, Shchemelev S N 2017 European Research Studies Journal XX (3B) 326

5. 2017 The program "Digital Economy of the Russian Federation", approved by order of July 28, No. 1632

6. Aptekman A, Kalabin V 2017 Digital Russia: a new reality Digital (McKinsey) http://www.tadviser.ru/images/c/c2/Digital-Russia- report.pdf

7. Laux J, Macaulay J, Noronha A, Wade M 2018 The digital whirlwind: how to defeat digital innovators with their own weapons (Moscow: Eksmo)

8. Mathews M R 2009 International review of Business Research Papers 5(2) 329 
9. Evstafyeva E, Kislaya I, Kruchanova I 2019 Proceedings of the 4th International Conference on Social, Business and Academic Leadership http://10.2991/icsbal19.2019.26/

10. Godina O V, Kosenkova Y Y, Maksimenko L S, Mezentseva Y R, Shcherbakova T A 2019 Advances in Intelligent Systems and Computing 72 doi.org/10.1007/978-3-31990835-9 14

11. Parker J, Chaudari S 2017 Platform revolution. How network markets are changing economies and how to make them work for you (Moscow: Mann, Ivanov and Ferber)

12. Krokhicheva G E, Yu R Mezentseva, Izvarina N Yu, Sidorenko E N 2005 Advances in Economics, Business and Management Research 139 194-199 https://doi.org/10.2991/aebmr.k.200509.036/

13. Melanie S 2017 Blockchain: The Scheme of the New Economy Olimp-Business (M.: Publishing House, )

14. Franks B 2016 The revolution in analytics: How to improve your business with operational analytics in the Big Data era (Moscow: Alpina Publisher) 